\title{
Mbarara University Research Training Initiative: Experiences and Accomplishments of the MEPI Junior D43 TW0I0I28 Award in Uganda
}

\author{
Edith K Wakida $\mathbb{D}^{\prime}$ \\ Clara D Atuhaire' \\ Christine K Karungi ${ }^{1}$ \\ Samuel Maling ${ }^{2}$ \\ Celestino Obua (iD ${ }^{3}$ \\ 'Office of Research Administration, \\ Mbarara University of Science and \\ Technology, Mbarara, Uganda; \\ ${ }^{2}$ Department of Psychiatry, Faculty of \\ Medicine, Mbarara University of Science \\ and Technology, Mbarara, Uganda; ${ }^{3}$ Office \\ of the Vice Chancellor, Mbarara \\ University of Science and Technology, \\ Mbarara, Uganda
}

\begin{abstract}
Objective: In 2015, Mbarara University of Science and Technology was awarded the Mbarara University Research Training Initiative (MURTI) under grant number D43 TW010128 to build capacity of junior faculty to become the next generation of researchers in Africa. In this paper, we document the experiences and achievements of the research capacity building efforts at MUST.
\end{abstract}

Methods: We conducted a descriptive evaluation study which involved document review and in-depth interviews. We used "Reach" and 'Effectiveness' from the RE-AIM framework to guide the document review, and the organizational theory of implementation effectiveness to guide the in-depth interviews.

Results: In the MURTI program, we conducted 17 short courses between August 2015 and July 2021, a total of 6597 attendances were recorded. The most attended courses were responsible conduct of research $(n=826)$, qualitative research methods $(n=744)$, and data management $(n=613)$. Thirty-three fellows were recruited and funded to conduct mentored research leading to 48 publications and 14 extramural grant applications were yielded. From the in-depth interviews, the participants appreciated the research training program, the enhanced research skills attained, and the institutional capacity built. They attributed the success of the program to the training approach of using short courses, readiness of the junior faculty to change, and the supportive environment by the mentors and trainers in the program.

Conclusion: The D43 TW010128 research training grant-built capacity for the junior faculty at MUST, enhanced their research skills, promoted research capacity institutionally and provided career development for the junior faculty. This was possible due to the positive attitude of the junior faculty (organizational readiness) to change and the supportive environment (mentors and trainers) during implementation of the grant. These two factors provided a favorable institutional climate that guaranteed success of the funding goals.

Keywords: MEPI junior faculty, D43 TW010128, MURTI, evaluating implementation, mentored research

\section{Introduction}

In 2010, the US President's Emergency Plan for AIDS Relief (PEPFAR) partnered with the US National Institutes of Health (NIH) and the US Health Resources and Services Administration (HRSA) to establish the Medical Education Partnership Initiative (MEPI) to support medical education in sub-Saharan Africa (SSA) while enhancing research capabilities and ensuring sustainability. ${ }^{1}$ HRSA and NIH announced the first MEPI grants in October 2010 and invested a total of
Correspondence: Edith K Wakida Tel +256782685541

Email ediwakida@must.ac.ug 
\$130 million over five years (2010-2015) to directly support medical schools in 12 sub-Saharan African countries. ${ }^{2}$ Mbarara University of Science and Technology (MUST) medical school was one of five medical schools in Uganda formed under the Medical Education for Equitable Services for All Ugandans (MESAU) consortium to address the medical education challenges in meeting the nation's health needs. ${ }^{3}$

While scientific, administrative, and infrastructure capacity was developed during the MEPI-MESAU program, the primary focus for MEPI was medical education for students. ${ }^{4}$ The program did not address research capacity for junior faculty and yet there is documented faculty shortages in basic and clinical sciences, inadequate linkage with other medical research and education centers in Africa and abroad, and little use of external accreditation in SSA. ${ }^{2,5}$ As a result, MUST, in partnership with researchers from Massachusetts General Hospital (MGH) and Harvard School of Public Health (HSPH), responded to the call for Research Training for Career Development of Junior Faculty in the MEPI institutions.

MUST was awarded the Mbarara University Research Training Initiative (MURTI) under grant number D43 TW010128 (August 2015 - July 2020) to build capacity of junior faculty to become the next generation of researchers in Africa. ${ }^{4}$ The specific aims included: 1) developing research expertise of junior faculty in HIV prevention and treatment, particularly in rural southwestern Uganda; 2) building the capacity of Ugandan junior faculty to develop novel, evidence-based diagnostic and treatment strategies for cardiovascular diseases and neurological disorders in rural populations to address priority health needs; 3) preparing junior faculty for research careers addressing mental health disorders in rural Uganda; and 4) equipping junior faculty with the administrative ability, research ethics, and research communication capacities necessary to succeed as the next generation of independent investigators in Uganda.

The MURTI ${ }^{4}$ adopted a model which involved shortterm focused research capacity training and mentorship over a two-year period. The trainees were paired to two mentors (Ugandan and US based) so that they could benefit from the different experiences. The trainees were also provided with seed grants to conduct mentored research and disseminate the findings in peer review journals and scientific conferences. Progress was monitored using individual development plans (IDPs) that were developed with the mentors. Trainee performance was reported to the program implementation committee (PIC) monthly and to the training advisory committee (TAC) quarterly. Additionally, MUST received an administrative supplement to expand on the MURTI scientific areas to include Alzheimer's Disease and its related dementias.

The motivation for the evaluation was to determine the usefulness of the D43 TW010128 MEPI junior faculty research training grant at MUST by documenting the experiences and achievements of the MURTI and MADRI programs and share lessons learned.

\section{Methods \\ Study Design}

This was a descriptive evaluation study which involved document review and in-depth interviews to determine the usefulness of the D43 TW010128 MEPI junior faculty training grant at MUST and document the experiences and achievements. We used "Reach" and 'Effectiveness' from the RE-AIM (Reach, Effectiveness, Adoption, Implementation, Maintenance) framework ${ }^{6,7}$ to guide the document review, and the organizational theory of implementation effectiveness ${ }^{8}$ to guide the in-depth interviews (Supplementary Tables S1 and $\underline{\mathrm{S} 2}$ ).

\section{Description of the D43 TW0I0I28 Training Program} The D43 TW010128 training program was a parent award to MUST under the title "Mbarara University Research Training Initiative (MURTI)" from August 2015 July 2020 with a one-year no-cost extension to July 2021. The MURTI had a one-year administrative supplement D43 TW010128-04S1 in August 2018 July 2019 under the title "Mbarara Alzheimer"s Disease and Related Dementias Initiative (MADRI)'. The MURTI provided in-depth training and mentored research to 21 junior faculty in HIV prevention and treatment, CVDs, neurological disorders, and mental health scientific areas, as well as research capacity building short courses annually for all the grant period. The MADRI expanded on the MURTI scientific areas by training 12 junior faculty in Alzheimer's disease and its related dementias ( $\mathrm{AD} /$ ADRD). The addition of AD/ADRD to MURTI activities was to enable the team to form a basis for future research given the paucity of information in the AD/ADRD and its growing importance in the region.

Description of the "Reach", "Effectiveness" and "organizational theory of implementation effectiveness" 
- Reach. This represents the proportion of individuals who are willing to participate in a given initiative and how representative they are compared to the target population. ${ }^{7,9}$ In this evaluation, we were interested in the proportion of junior faculty that participated in the MURTI research capacity short courses that were offered at MUST within the D43 TW010128 funding period. Our study measure was the percentage of junior faculty segregated by course attended, gender, field (health or non-health), and category of employment (teaching or non-teaching).

- Effectiveness. This describes the impact of an intervention or program on important outcomes, including potential positive and negative effects. ${ }^{7,9}$ We measured the success rate of the D43 TW010128 grant against set deliverables including scientific manuscripts and extramural grants awarded. This was measured by the percentage of junior faculty at MUST with publications acknowledging the D43 TW010128 funding, and those awarded extramural grants.

- Organizational theory of implementation effectiveness. We looked at three constructs including organizational readiness for change, implementation policies and procedures, and implementation climate.

- Organizational readiness for change. This refers to organizational members' change commitment and change efficacy to implement organizational change. ${ }^{8,10}$ We explored the participants perceptions about the training program and what they thought were the collective actions that helped them to go through the training program.

- Implementation policies and procedures. Organizational policies and procedures can positively or negatively affect the organizational members' appraisals of task demands, resource availability, and situational factors. ${ }^{11}$ We were interested in the policies and procedures in place to ensure successful implementation of the training program and what the participants thought about them in relation to fostering change commitment at MUST.

- Implementation climate. Positive organizational climate (eg, good working relationships) are important in promoting organizational readiness. ${ }^{8,12} \mathrm{We}$ explored the participants thoughts about whether the research training programs (MURTI and MADRI) were needed, important, beneficial, or worthwhile.

\section{Study Participants}

We interviewed MUST junior faculty who were trainees in the MURTI program and the MADRI administrative supplement.

\section{Data Collection}

We had both primary and secondary data sources in this study. The primary data source comprised of junior faculty at MUST who directly benefited from the D43 TW010128 grant through research capacity building and mentored research, while the secondary data sources comprised of program reports, course registration sheets and PubMed database.

We used two data collection methods: a) document review of course attendance registration sheets, online databases for scientific manuscripts acknowledging funding from D43 TW010128 grant, and program reports for extramural grants; and b) in-depth interviews with junior faculty trainees who benefited from either the MURTI or MADRI training programs.

\section{Document Review Process}

We reviewed documents from three data sources (course attendance registers, online databases, and program reports) and extracted data using a checklist developed based on the intended outcomes.

- Course attendance registration sheets - a checklist with the items: course offered, date, sex, teaching (faculty), non-teaching (administrators and research staff), and health/non-health fields was used to guide the data extraction from the course registration sheets of seventeen short courses offered by the D43 TW010128 grant annually between August 1, 2015, to July 31, 2021.

- Online databases - we searched PubMed and Google Scholar for the D43 TW010128 number and extracted the PubMed Central identifier (PMCID) and/or the Digital Object Identifier (Doi).

- Program reports - all annual programmatic reports on D43 TW010128 grant were reviewed for any extramural grants awarded to MUST between 2015 and 2021. The awardees were either trainees (directly) or key personnel/investigators (indirectly) who took part in the training and/or received research administrative support and grant submission through the Office of Research Administration. We extracted data on the funder, grant number, and funding period. 
All participant entries were de-identified and transformed to an electronic version in Microsoft Access. On each data collection day, the research assistants reviewed one of the data sources (course registration sheets, online databases, or program reports) and extracted relevant data using the checklist. At the end of each data collection day, the study principal investigator $(\mathrm{EKW})$ reviewed the extracted data from the two reviewers (PK and $\mathrm{CA}$ ) for correctness and completeness. Instances of incomplete and/ or conflicting data were resolved through discussion and any further disagreements were settled through reanalyzing the data sources. Entries that did not have all the desired outcomes were excluded.

\section{In-Depth Interview Process}

Two research assistants (CM and MT) external to the D43 TW010128 grant, with expertise in qualitative research techniques, interviewed the junior faculty beneficiaries at MUST using semi-structured questions based on the organizational theory of implementation effectiveness. The aim of the qualitative interviews was to verify information gleaned in the document review, fill in gaps, and answer key questions about implementation effectiveness of the training programs.

\section{Data Management and Analysis Document Review}

The Microsoft Access data entry form had checks for quality control. The data from course attendance registration were exported to IBM SPSS ver 20 for analysis. Using descriptive statistics, data were analyzed in two segments (Years 1-3 for mid-term performance, and Years 4-6 for end-line performance) for frequencies.

\section{In-Depth Interview Process}

We used the framework analysis ${ }^{13}$ which included transcription, familiarization with the data, coding, developing and applying the analytical framework, charting data into the framework matrix, and interpreting the data.

- Transcription - CM and MT transcribed the interviews. To ensure similarity, they both examined the transcripts for comparable formatting until satisfied that any inconsistencies were resolved. All transcripts were reviewed for errors by listening to the audiorecording and reading the transcripts simultaneously.

- Familiarization with the data - The research team read and re-read each transcript and listened to the audio-recorded interviews to familiarize with the data set while making notes about their initial impressions before analysis.

Coding - this was guided by three constructs (ie, Organizational readiness for change, implementation policies and procedures, and implementation climate); the transcripts were independently coded.

- Developing an analytical framework - after coding and discussing each coded sections, we discussed in terms of why we had interpreted the sections as meaningful, and how useful they were for answering the evaluation questions.

Applying the analytical framework - the final analytical framework was applied to each transcript using the computer-assisted qualitative data analysis software ATLAS.ti version 8. Transcripts were imported into ATLAS.ti for indexing, highlighting each meaningful passage of text and attaching an appropriate code.

- Charting data into the framework matrix - all coded data were summarized in a matrix (one row per participant and one column per code) for each theme. Data were abstracted from the transcripts for each participant and code, summarized verbatim and inserted into the corresponding cell in the matrix.

Interpreting the data - we reviewed the matrix based on the a priori themes, making connection within and between participants while constantly referring to the original evaluation objectives. We grouped similar quotes under relevant themes and identified illustrative quotes as presented in the results.

\section{Results}

In this section, we present results from a document review and in-depth interviews with junior faculty beneficiaries.

\section{Document Review}

\section{MURTI Short Course Attendance}

Review of the course attendance registration showed a record of 6,597 attendances for the funding period August 2015 to July 2021. Overall, there were more males in attendance $(3,974 ; 60.2 \%)$ than the females $(2,623 ; 39.8 \%)$. A comparison of the findings at two time points ie, mid-term (August 1, 2015, to July 31, 2018) and end-line (August 1, 2018, to July 31, 2021) recorded 
Table I Overview of Implementation of Research Capacity Training Short Courses

\begin{tabular}{|c|c|c|c|c|c|c|}
\hline & \multirow[t]{2}{*}{ Course } & \multicolumn{2}{|c|}{ Trained Years I-3 } & \multicolumn{2}{|c|}{ Trained Years 4-6 } & \multirow[t]{2}{*}{ Overall Participation (\%) } \\
\hline & & Female & Male & Female & Male & \\
\hline I. & Responsible conduct of research & 270 & 320 & 91 & 145 & $826(12.5)$ \\
\hline 2. & Good Clinical Practice & 74 & 254 & 24 & 47 & $399(6.0)$ \\
\hline 3. & Literature search and EndNote & 94 & 157 & 116 & 146 & $513(7.8)$ \\
\hline 4. & Fundamentals of Molecular diagnostics & 68 & 207 & 53 & 180 & 508 (7.7) \\
\hline 5. & Measurement Tools development & 32 & 49 & 85 & 78 & 244 (3.7) \\
\hline 6. & Archiving and Samples & - & - & 13 & 14 & $27(0.4)$ \\
\hline 7. & Grant writing & 48 & 142 & 107 & 161 & $458(6.9)$ \\
\hline 8. & Qualitative Research methods & 235 & 278 & 109 & 122 & $744(11.3)$ \\
\hline 9. & Quantitative Research methods & 95 & 148 & 90 & 95 & $428(6.5)$ \\
\hline 10. & Implementation Science & 128 & 116 & 65 & 60 & $369(5.6)$ \\
\hline II. & Scientific Manuscript writing & 99 & 95 & 65 & 86 & $345(5.2)$ \\
\hline 12. & Financial Management & 101 & 102 & 18 & 22 & $243(3.7)$ \\
\hline 13. & Good Clinical Laboratory Practice & 35 & 72 & 46 & 60 & $213(3.2)$ \\
\hline 14. & Systematic Review of Literature & 50 & 65 & 70 & 93 & $278(4.2)$ \\
\hline 15. & Data Management and Mining & 121 & 218 & 113 & 161 & $613(9.3)$ \\
\hline 16. & Developing policy briefs & 27 & 22 & 74 & 216 & $339(5.1)$ \\
\hline \multirow[t]{2}{*}{17.} & Intellectual Property & 7 & 43 & - & - & $50(0.8)$ \\
\hline & Overall total & 1484 & 2288 & 1139 & 1686 & $6597(100)$ \\
\hline
\end{tabular}

participation of 3,772 (1,484 females and 2,288 males), and 2,825 (1,139 females and 1,686 males) respectively. Table 1 presents the overview of implementation of research capacity training short courses offered.

Table 1 shows that over the five years of the training program, the most attended courses were: responsible conduct of research (12.5\%, 826/6597 participants); qualitative research methods $(11.3 \%$, $744 / 6597$ participants), and data management and mining (9.3\%, 613/6597 participants). While a number of courses attracted relatively equal numbers of participants during the first and the last three years, we, however, found differences in course attendances during the two periods of training, where in the first three years of training, the following courses attracted more participants compared to the last three years: responsible conduct of research (590 vs 236); Good clinical practice (328 vs 71 ); qualitative research methods (513 vs 231 ); implementation science ( 244 vs 125 ); and financial management (203 vs 40). Comparatively, the following courses attracted more participants in the last three years compared to the first three years: grant writing (268 vs 190); and developing policy briefs (290 vs 49). The least attended courses were: archiving samples $(0.4 \%, 27$ participants) and intellectual property $(0.8 \%, 50$ participants).
Training was open to both teaching (faculty) and nonteaching (administrators and research) staff from health and non-health fields. The overall distribution of participants, by category, showed that most of the participants were from health-related fields $(55.9 \%, 3687 / 6597))$, and were mostly teaching faculty $(66.1 \%, 4358 / 6597)$, as illustrated in Table 2. Specifically, we found that, implementation of science, systematic review of literature and good clinical laboratory practice courses, attracted nearly comparable numbers of teaching and non-teaching participants, while qualitative research methods attracted more non-health teaching staff.

\section{Publications Attributed to the D43 TW0I0I28 Funding}

We present a total of 48 publications attributed to the D43 TW010128 under specific scientific research areas that included HIV prevention and treatment, cardiovascular diseases, neurological disorders, mental health, Alzheimer's and its related dementias, and spin-off publications broken down as follow:

(a) HIV prevention and treatment research area. We realized 07 publications from the MURTI trainees in this area: (i) PMC6486443; ${ }^{14}$ (ii) PMC $8183159 ; ;^{15}$ (iii) PMC5288444; ${ }^{16}$ (iv) PMID: $34292430 ;{ }^{17}$ and (v) 
Table 2 Overall Distribution of Participants per Course by Category*

\begin{tabular}{|c|c|c|c|c|c|}
\hline & Course Offered & Health n (\%) & Non-Health n (\%) & Teaching n (\%) & Non-Teaching n (\%) \\
\hline I. & Responsible conduct of research & $460(55.7)$ & $366(44.3)$ & $570(69.0)$ & $256(31.0)$ \\
\hline 2. & Good Clinical Practice & $346(86.7)$ & $53(13.3)$ & $350(87.7)$ & $49(12.3)$ \\
\hline 3. & Literature search and EndNote & $276(53.8)$ & $237(46.2)$ & $370(72.1)$ & $143(27.9)$ \\
\hline 4. & Fundamentals of Molecular diagnostics & 47I (92.7) & $37(7.3)$ & $474(93.3)$ & $34(6.7)$ \\
\hline 5. & Measurement Tools development & $|4|(57.8)$ & $103(42.2)$ & $170(69.7)$ & $74(30.3)$ \\
\hline 6. & Archiving and Samples & $16(59.3)$ & II (40.7) & $16(59.3)$ & II (40.7) \\
\hline 7. & Grant writing & $280(61.6)$ & $178(38.4)$ & $313(68.3)$ & $145(3 \mid .7)$ \\
\hline 8. & Qualitative Research methods & $288(38.7)$ & $456(6 \mid .3)$ & $436(58.6)$ & $308(4 I .4)$ \\
\hline 9. & Quantitative Research methods & $190(44.4)$ & $238(55.6)$ & $252(58.9)$ & $176(4 \mid .1)$ \\
\hline 10. & Implementation Science & $155(42.0)$ & $2 \mid 4(58.0)$ & $187(50.7)$ & $182(49.3)$ \\
\hline 11. & Scientific Manuscript writing & $193(55.9)$ & $152(44.1)$ & $220(63.8)$ & $125(36.2)$ \\
\hline 12. & Financial Management & $3 \mid(\mid 2.8)$ & $212(87.2)$ & $38(15.6)$ & $205(84.4)$ \\
\hline 13. & Good Clinical Laboratory Practice & $94(44.1)$ & $119(55.9)$ & $112(52.6)$ & $101(47.4)$ \\
\hline 14. & Systematic Review of Literature & $\mid 43(5 \mid .4)$ & $135(48.6)$ & $159(57.2)$ & $119(42.8)$ \\
\hline 15. & Data Management and Mining & $321(52.4)$ & $292(47.6)$ & $377(6 \mid .5)$ & $236(38.5)$ \\
\hline 16. & Developing policy briefs & $270(75.2)$ & $69(24.8)$ & $272(75.8)$ & $67(24.2)$ \\
\hline \multirow[t]{2}{*}{17.} & Intellectual Property & $12(24.0)$ & $38(76.0)$ & $42(84.0)$ & $8(16.0)$ \\
\hline & Overall total & 3687 (55.9) & $2910(44.1)$ & $4358(66.1)$ & 2239(33.9) \\
\hline
\end{tabular}

Note: *The participant attendance varied from course to course, with percentage attendance for each category computed from the total attendance per course.

PMC6588214; ${ }^{18}$ (vi) https://dx.doi.org/10.4314/ahs. v21i3.14; ${ }^{19}$ (vii) PMC6614012. ${ }^{20}$

(b) Cardiovascular diseases research area. We realized 13 publications from the MURTI trainees in this area: (i) PMC5766276 $^{21}$ (ii) https://doi.org/10.29392/001c. 19464; ${ }^{22}$ (iii) PMC7470164; ${ }^{23}$ (iv) PMC7218768; ${ }^{24}$ (v) PMC8077796; ${ }^{25}$ (vi) https://doi.org/10.1007/ s13410-021-00944-6; ${ }^{26}$ (vii) https://doi.org/10. 11604/pamj.2021.39.142.28620 (viii) PMC736 $7467 ;^{28}$ (ix) PMC6877961; $;^{29}$ (x) PMC7396089; ${ }^{30}$ (xi) $\mathrm{PMC} 7004860 ;{ }^{31}$ (xii) PMC6641537; ${ }^{32}$ (xiii) PMC7592727. ${ }^{33}$

(c) Neurological disorders and stroke research area. We realized 05 publications from the MURTI trainees in this area: (i) PMC5659749; ${ }^{34}$ (ii) PMC $7341388 ;^{35}$ (iii) $\mathrm{PMC} 6716529 ;^{36}$ (iv) PMC 8 $276422 ;^{37}$ (v) PMC6309793. ${ }^{38}$

(d) Mental health research area. We realized 09 publications from the MURTI trainees in this area: (i) $\mathrm{PMC} 636650 ;{ }^{39}$ (ii) $\mathrm{PMC} 5411062 ;^{40}$ (iii) $\mathrm{PMC} 6$ $289958 ;^{41}$ (iv) PMC6774805; ${ }^{42}$ (v) PMC6613367; P3 $^{43}$ (vi) PMC5423027; ${ }^{44}$ (vii) PMC6614012; ${ }^{20}$ (viii) PMC7750070; $^{45}$ (ix) $10.11604 /$ pamj-oh.2020.3.9.2 $5146{ }^{46}$

(e) Alzheimer's disease and its related dementias (AD/ ADRD). We realized 08 publications from the
MADRI trainees in this area: (i) PMC7544160;

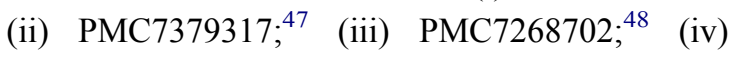
$\mathrm{PMC} 206770 ;{ }^{49}$ (v) PMC6935120; ${ }^{50}$ (vi) PMC $7158106 ;{ }^{51}$ (vii) PMC7011370. ${ }^{52}$

(f) Spin-off publications. We realized 06 publications as spin-offs from the D43 TW010128: (i) $\mathrm{PMC}_{5338542 ;}{ }^{4}$ (ii) $\mathrm{PMC} 6701610 ;{ }^{53}$ (iii) $\mathrm{PMC}$ $6292009 ;^{54}$ (iv) PMC6264616; ${ }^{55}$ (v) PMC63 $89192 ;^{56}$ and (vi) PMC8281638. ${ }^{57}$

\section{Extramural Grants Awarded to MUST}

Over the grant period, we recorded 14 extramural grants to MUST attributed to the D43TW010128 either directly through the former trainees or indirectly through the investigators, key personnel, or faculty. Most of the grants (10) were from the National Institutes of Health through Fogarty International Center, USA included: Trainees K43TW011004 (2018-2023), and K43 TW011929 (20212026), non-trainees - K43TW010388 (2016-2021), R25TW011210 (2018-2023), D43TW010128-04S1 (20182019), K43TW010715 (2017-2022), R25TW010507 (20182023), 3R25TW011210-03S1 (2020-2021), D43TW011632 (2020-2025), 3R25TW011210-03S2 (2021-2022). The other awards to trainees not FIC related included 5P30A1060355-14 subcontract MUST number: 1605051428; R21 CFAR administrative supplement; Micro- 
research:17M_MUS 02; and Friedrich-Baur-Stiftung, University of Munich, Germany: No.80736109.

\section{In-Depth Interviews}

We present the results along three thematic areas: Organizational readiness for change, Implementation policies and procedures, and Implementation climate.

\section{Theme I: Organizational Readiness for Change}

When asked what their perceptions were, about the MURTI and MADRI training programs, most of the MURTI beneficiaries reported enhanced research capacity skills, which resulted in improved student supervision, expanded professional networks, research career development, and that they were a motivation to their colleagues in the department fostering academic competition.

It facilitated career development, initially, I had little research engagement and vertical academic growth. This program was overwhelmingly acceptable, it motivated my department because I served as a role model. Winning the MURTI fellowship facilitated competition, faculty viewed it as an entry point to research development, and publication growth. ... faculty leadership appreciated the fellows' efforts in pushing departmental growth forward and supported the initiative ... those who had made attempts to apply for the MURTI fellowship appreciated the meritbased orientation of the program when selecting grantees. (MURTI trainee, cohort 4)

The MADRI beneficiaries were particularly impressed by the mentoring approach that was used, and the fact that they were able to realize research outputs in a short time. The participants who were on graduate programs reported that the MADRI was timely and that it had given them knowledge and skills that facilitated their academic journeys. One participant reported gaining interest in dementia from which she developed a research question for her master's program. She has since graduated, and is now mentoring an undergraduate research team with interest in dementia.

The training program was a good one, as a student we didn't pay particular attention to dementia, but given that Uganda's population is aging, the training was timely. I gained a lot of knowledge in dementia and, my research skills improved. In the one-year fellowship, we developed research proposals, collected data, analyzed it, and eventually wrote a manuscript. The skills I acquired were very useful,
I developed a research question which I used in my master's program, and I completed. I am currently mentoring an undergraduate student team and I am utilizing the skills I gained from MADRI program. (MADRI trainee 12)

As a program, we needed to know the collective actions that helped the trainees on both the MURTI and MADRI to successfully complete the training. For the MURTI, most participants reported that the clear leadership structure fostered successful completion of the training program. They received timely support whenever they needed it to facilitate their training including scientific, logistical, and administrative guidance as exemplified below:

MURTI had good leadership ... we had mentors, administrators, follow up meetings and reminders, so basically everything was set in place to make sure that you achieve your objectives. If we needed a particular training, we would apply for it and it would be given, if we needed to present our work at international conferences, they were facilitated. We were also facilitated on the issues of internet, and we were given laptops to do our work, I think the incentives made us feel the need to produce quality work for being a fellow. (MURTI Trainee Cohort 1)

The collective actions reported by the participants on MADRI training program as key to their success were the mentor-mentee relationship, teamwork, and availability of the program directors. That the program directors were always there during the training and provided support each time the trainees presented their progress, nobody was left behind regardless of the pace at which they worked; there was no way they could not progress with that kind of mentorship.

The teamwork and mentoring helped us to successfully go through the training program. It started with the training when we were inducted, after that we worked together through writing protocols until manuscripts. I am still riding on that experience up to now ... we used to work motivated that the investigators were coming to check on our progress step by step. Sometimes it was challenging to check on you and the progress made is very minimal, but I was encouraged that the program directors trusted me to drive the process. Close mentoring and teamwork built in us, and the support during financial management made it easy to successfully go through the program especially for those who were slower. (MADRI trainee 11) 


\section{Theme 2: Implementation Policies and Procedures}

When asked what implementation policies and procedures were in place to ensure successful implementation of the MURTI training program; most of the participants noted that the use of the individual development plan, as a guiding document to ensure that whatever was written was fulfilled, was very useful.

I think one of the procedures put in place to achieve the deliverables was the development of the IDP [individual development plan] and making sure that the Fellows follow it. What MURTI did was to look at your IDP critically, for example, if they see that there are those interested in qualitative methods, they get you a mentor with qualitative research skills ... so I really think their policies of trying to implement each trainee IDP and getting us conferences for international exposure was good. They would read through our abstracts before submitting for a conference ... I think they really put a lot into this. To me, it is the first and best mentoring experience I have had in my life; I am now one year into my $\mathrm{PhD}$ program, but nothing has been organized for me like what MURTI did. (MURTI Trainee cohort 3)

When the same question was asked to the MADRI participants, most of them referred to the policy which stated that no research funds would be advanced until they had received ethics clearance. Although it visibly seemed uncomfortable to them during the interviews, the participants noted that the policy helped them to adhere to their timelines and plans. They noted that they were expected to progress at the same pace, and that if they slowed down on any step, they would be excluded from the training as they would not meet the objectives of that session. Most of the participants appreciated that providing the timelines at the onset helped them to plan for the training program appropriately.

'We had timelines, so they would tell us that by this date you should have submitted your proposal for ethics approval, then by this date you should have collected data ... the training coordinator was constantly reminding us of our timelines and to submit monthly progress reports, so we would not sit back and relax, each of us had to fit in those timelines. The trainings were scheduled in a way that we had to move together, and no one was allowed to attend the training if an activity in the timeline had not been completed, for example, after data collection, we were supposed to go for data analysis training, it was communicated ahead of time, so we knew this date. ... to attend data analysis training, you needed to have collected data otherwise you would have nothing to analyze. The activities were communicated early enough to allow the Fellows to plan appropriately. (MADRI trainee 8)

We asked the participants what they thought about the policies and procedures that fostered commitment to change at MUST, given that, the more organizational members valued the change, the more they would want to implement it or have the resolve to engage in the courses of action involved in change implementation. We found that most policies and procedures especially those related to funded programs like the MURTI and MADRI were viewed from the lens of the benefits attached. In the MURTI for instance, the participants considered the recruitment process of the trainees as the policies and procedures to foster change commitment. They referred to the fact that whoever did not apply for the training would not be considered, and so the interested people would ensure that they applied on time to be considered, since they needed the knowledge and skills that were being offered. They looked at that as commitment to change.

... when it comes to getting knowledge, the more knowledge you get, the better you become ... I think that people are committed other than we the Fellows [trainees]. When MURTI trainings are advertised on the website, if you don't book early, you miss out; so, people apply. That shows commitment ... people who don't apply need to change because the more you are exposed, the better you become, and you can see everyone wants to move from one step to another, but how do you do that if you don't add on what you have? To me I think everyone is committed to see that they are moving ahead rather than being left behind, and of course the trainings can tell it ... if there is a call for training and some people are taken and others are complaining about not being taken, it shows that people are committed to change. (MURTI trainee, cohort 1)

The other policy that the participants referred to which fostered change commitment was the MURTI program holding the trainees' last-months stipend until they had published their research work. Participants acknowledged that they were aware of the policy when they took on the fellowship and that they needed to adhere to the contract they signed. Most of them thought that such policies were good especially for monitoring progress of the trainees. 
You could not have funds released to you before you had the ethics approval, or you could not access the last six months stipend until your research work was published ... these sound hard policies, but because we knew about them when we accepted the award, we had to work hard. ... it is very clear, to have the money, publish, after all I agreed that I must publish. I think these stringent measures were necessary to help in monitoring our progress because the way some people can take up something and then abandon it, of course that spoils the name of the university. (MURTI trainee, cohort 4)

Similarly, in MADRI, the participants thought that the policies and procedures that had been put in place were meant to foster commitment to change including keeping the trainee on track. They acknowledged that the policies were very clear from the onset, indicating the timelines and expected deliverables. They thought that there was need for continuous monitoring of activities to foster performance, because in a university setting, there are competing priorities.

I think the policies put in place are important to help the fellows to keep on track ... a house which doesn't have rules, people do things the way they want, and you will not have results at the end of the day. We were given guidelines at onset from formulating a research topic to when we would produce a manuscript ... I think with the expected output communicated and the means of achieving the outputs available, there is improved performance. In the university setting, even when resources have been provided, there's need for continuous monitoring because people are doing different projects. Otherwise giving the resources and timelines without supervising, the people may get involved in other things and fail to perform. MADRI trainee 9

Some participants were of the view that it was unrealistic for awardees not to expect the MADRI program to have policies and procedures to foster change commitment. They believed that these were key to facilitating attainment of deliverables within the one-year of the award. As a matter of fact, one participant acknowledged that it was a learning experience, seeing that it was possible to set objectives in the shortest possible time and successfully achieve them. Although viewed as hectic, most participants appreciated the procedures in place to facilitate financial management.

'It's not a matter of giving someone an award and then you let the person be, what you need at the end of the day are deliverables. You need to have a road map on how this person is going to deliver ... this project was short, just one year but it was tailored to fit within the period. This taught me that even if it is one year, it is possible to gain experience provided you know the objectives and the time frame. When it came to accountability and accessing the funds, the procedures were hectic, but it was a good learning experience on how to manage funds. There were no delays, at least the processes were smooth, that was of great importance. (MADRI trainee 1)

\section{Theme 3: Implementation Climate}

In evaluating implementation climate, we were looking for whether the research training programs were viewed by the participants as needed, important, beneficial or worthwhile, generally measured through skills obtained, incentives/disincentives, and the absence of obstacles. All the participants agreed on the importance and benefits of the training programs as illustrated below:

If you don't have research skills and you are in the academia, how will you be able to supervise the students? How will you do it when you cannot write and publish? Even in the clinical field with all these diseases coming up, how will you manage them if you don't conduct research? I think that to be recognized or to move with the world, you need the research skills then you will read, write, become a critic to peoples work, and you come up with solutions to problems. I therefore say that the MURTI training program is needed, it is very important, and beneficial. (MURTI trainee, cohort 3)

There's a common saying that you don't know what you don't know ... it is not until you go for such trainings that you begin looking at things with different lenses. Like many other people, I did not think that dementia was a common problem in Africa, but from the trainings and research, I discovered that indeed it is a big problem which was being ignored. This training program is very important, we are now more knowledgeable about dementia and how to promote its care. (MADRI trainee 5)

The participants found it intriguing and at the same time worthwhile, that the intended beneficiaries had not participated in the grant applications and yet it ushered them into the training programs. This motivated them to successfully implement the activities that they set out to do and wished the same for other junior faculty or researchers given the accrued benefits as expressed in the two views from the different training programs. 
I found it a unique opportunity for people to write a grant while the beneficiaries are people who didn't participate in the writing ... We have been empowered in knowledge and skills in research and I think that this is a very necessary program especially for junior faculty and researchers to build their confidence and skills. I attribute this program to my $\mathrm{PhD}$ completion ... one of my first papers was from MURTI before I forwarded more papers for my $\mathrm{PhD}$ work. I think I am a better person in terms of research and the ability to apply for grants. If I hadn't participated in the MURTI program, I would still be fearful, docile, or just lost in the process. If there was an opportunity to apply for a similar grant, I would really encourage the institution to apply for it. (MURTI trainee, Cohort 2)

It was very beneficial, I got experience engaging the community about dementia, and I saw their willingness to continue working with me. I was able to get a publication out of my work ... even if it was just one year, it was beneficial; no one should push and say that such projects can't be fulfilled in a short time. (MADRI trainee 3)

\section{Discussion}

This was an end-line evaluation to determine the usefulness of the D43 TW010128 MEPI junior faculty research training grant at Mbarara University of Science and Technology (MUST) offered through the MURTI (parent award) and MADRI (administrative supplement). We used an implementation model of inviting as many junior faculty at MUST as were interested in attending the research capacity training, while competitively selecting and concentrating on a few junior faculty (Fellows/trainees) for specialized training in specific scientific areas of focus (HIV, mental health, CVD and neurological diseases $).{ }^{4}$ Using short training programs while covering multiple competencies allowed the D43 TW010128 program at MUST to provide a wide range of knowledge and skills not only to the Fellows/trainees but to the wider community of junior faculty. ${ }^{58}$

The findings in the study are demonstrated evidence of tremendous positive changes of products made by junior faculty at MUST attributable to the D43 TW010128 MEPI junior faculty funding including publications and new grants awarded. This demonstrates that research training can enhance skills, promote research capacity, and provide career development for junior faculty as shown by the numbers of research outputs and publications from the mentored research. Funding, such as the D43TW010128, through the implementation strategies, as was employed under MURTI and MADRI programs, also improve mentorship and provide opportunities for expanding professional networks, where, in this case, mentors comprised experts from the USA and Ugandan institutions.

\section{Document Review}

Using the RE-AIM framework, we have determined that the greatest impact of the training program was attained through the short courses with the most popular being the responsible conduct of research (826 participants) followed by the qualitative research methods (744 participants) and thirdly, data mining and management (613 participants). The courses attracted both health and nonhealth participants with a total of 6597 attendances, the majority being health professional junior faculty. Another indication of the impact of the D43WT010128 funding was the ability of the 21 MURTI and 12 MADRI trainees to author approximately 48 publications as well as submit extramural grant applications to the $\mathrm{NIH}$, a feat which would not have been possible without the funding. Auranen and Nieminen ${ }^{59}$ found that funding environments vary across institutions, but of importance is the efficiency of the university system that contributes to productivity of publications. In this study, we have shown that, in addition to the funding, well-structured training models ${ }^{4,60}$ and the motivation of the trainees and their mentors were important factors to the high productivity from the D43WT010128 grant.

\section{In-Depth Interviews}

From the in-depth interviews, with the direct beneficiaries, the methods used in implementing the grant were important factors in the success of the grant. Individually and collectively their views were that everyone (trainees, mentors, trainers, and organizers) played an essential role towards the success of the grant. This is demonstration that organizational readiness is a shared resolve, because, implementing complex organizational changes involves collective action by many people, each of whom contributes to the implementation effort. Members can commit to implementing an organizational change because they want to (value the change), they have to (little choice), or because they ought to (feel obliged). ${ }^{61}$ In this study, our findings were inclined towards members deriving more value to the change as was severally expressed by the participants during the interviews. Additionally, Klein and Sorra postulate that implementation climate reflects 
organizational members' gestalt perceptions of the expectations, support and rewards for innovation use, ${ }^{62}$ thus proving that, a capacity building grant such as the D43WT010128, that supported the MURTI and MADRI research capacity training, drew success from the positivity of the junior faculty towards change and the favorable institutional implementation climate.

\section{Limitations}

The data collected from the document review were records extracted based on participant attendances, and that some courses attracted more participants than others leading to variations in the level of attendances per course, which ranged from 27 to 826 attendances. As such we could not carry out any meaningful statistical analysis. Nonetheless, during the interviews the enthusiasm of the junior faculty showed that well-attended courses (responsible conduct of research, qualitative research methods, and data management and mining) were courses that they felt would build their capacity. The courses that attracted few participants (archiving and samples, and intellectual property) could have been due to the limited and very specific application of the skills attained after the training in those areas.

Furthermore, we also had some limitations in the qualitative aspect of this study since we could not conduct focus group discussion, which would have supported the findings from in-depth interviews. The study was conducted during the COVID-19 lockdown, where group meetings or gatherings were prohibited as part of the COVID-19 containment and prevention measure. We were, therefore, not able to explore deeper into the perspectives and experiences of the trainees who benefited from the program since we could not conduct focus group discussions.

\section{Conclusion}

The study findings show that funding from the D43 TW010128 MEPI junior faculty research training caused tremendous positive change among junior faculty at MUST. Funded research training therefore can enhance skills, promote research capacity, and provide career development for junior faculty as shown by the numbers of research outputs, new grants awarded, and provide opportunities for expanding professional networks. This shows the importance of funding research capacity for junior faculty, which ultimately spurs research interests and publications. The positive attitude of the junior faculty (organizational readiness) to change, and the supportive environment by the mentors and trainers during the implementation of the grant, further provides favorable institutional climate that guaranteed success of the funding goals.

\section{Ethics and Consent to Participate}

The study was approved by the Mbarara University of Science and Technology Research Ethics Committee (MUREC 1/7) 19/12-19. All participants provided written informed consent before each in-depth interview. The participants were aware about the need for publications out of the D43 TW010128 supported work, they were informed that participation was voluntary, and that they had the freedom to withdraw from the study at any time with no repercussion. They were assured about protection of their privacy and that no identifiable information would be included in the publication. This was in addition to conducting the interviews in private spaces by trained interviewers who were external to the project. We respected individual autonomy to participate in the study by not including those who declined to participate, all who consented; no participant withdrew from the study.

\section{Acknowledgments}

We would like to acknowledge the junior faculty, the mentors and trainers for their tremendous support during the implementation of the MURTI and the MADRI administrative supplement research training program.

\section{Author Information}

Edith Wakida is the Research Manager in the Office of Research Administration at Mbarara University of Science and Technology and key person responsible for research administration, ethics and communication on the MURTI Program. Samuel Maling is an Associate Professor of Psychiatry, former Dean Faculty of Medicine, Mbarara University of Science and Technology and the Program Director II in charge of the day-to-day activities of MURTI Program. Celestino Obua is a Professor of Pharmacology, the Vice Chancellor Mbarara University of Science and Technology and the contact Program Director for the MURTI Program.

\section{Funding}

This publication was supported by the Fogarty International Center (NIH Common Fund, Office of Strategic Coordination, Office of the Director (OD/OSC/ $\mathrm{CF} / \mathrm{NIH}$ ); Office of AIDS Research, Office of the Director 
(OAR/NIH); National Institute of Mental Health (NIMH/ $\mathrm{NIH}$ ); National Institute of Neurological Disorders and Stroke (NINDS/NIH)) of the National Institutes of Health under Award Number D43 TW010128. The content is solely the responsibility of the authors and does not necessarily represent the official views of the National Institutes of Health.

\section{Disclosure}

The authors declare no conflicts of interest for this work.

\section{References}

1. Collins FS, Glass RI, Whitescarver J, Wakefield M, Goosby EP. Public health. Developing health workforce capacity in Africa. Science. 2010;330(6009):1324-1325. doi:10.1126/science.1199930

2. Kilmarx PH, Katz F, Razak MH, Palen J, Cheever LW, Glass RI. The medical education partnership initiative: strengthening human resources to end aids and improve health in Africa. Acad Med. 2019;94(11):1704-1713. doi:10.1097/ACM.0000000000002489

3. Mafigiri DK, Ayebare F, Baingana RK, Okello E, Sewankambo NK. Medical Education for Equitable Services for All Ugandans (MESAU) consortium: development and achievements. Acad Med. 2014;89(8 Suppl):S65-68. doi:10.1097/ACM.0000000000000333

4. Wakida E, Maling S, Obua C. Mbarara University research training initiative: a spin-off of the medical education partnership initiative in Uganda. Advan Med Educ Pract. 2017;8:527. doi:10.2147/AMEP. S138024

5. Mullan F, Frehywot S, Omaswa F, et al. Medical schools in sub-Saharan Africa. Lancet (London, England). 2011;377 (9771):1113-1121. doi:10.1016/S0140-6736(10)61961-7

6. Glasgow RE, Vogt TM, Boles SM. Evaluating the public health impact of health promotion interventions: the RE-AIM framework. Am J Public Health. 1999;89(9):1322-1327. doi:10.2105/ AJPH.89.9.1322

7. Glasgow RE, Dickinson P, Fisher L, et al. Use of RE-AIM to develop a multi-media facilitation tool for the patient-centered medical home. Implement Sci. 2011;6:118. doi:10.1186/1748-5908-6-118

8. Weiner BJ, Lewis MA, Linnan LA. Using organization theory to understand the determinants of effective implementation of worksite health promotion programs. Health Educ Res. 2008;24(2):292-305. doi:10.1093/her/cyn019

9. Shaw RB, Sweet SN, McBride CB, Adair WK, Ginis KAM. Operationalizing the reach, effectiveness, adoption, implementation, maintenance (RE-AIM) framework to evaluate the collective impact of autonomous community programs that promote health and well-being. BMC Public Health. 2019;19(1):1-14. doi:10.1186/ s12889-019-7131-4

10. Weiner BJ, Amick H, Lee S-YD. Conceptualization and measurement of organizational readiness for change: a review of the literature in health services research and other fields. Med Care Res Rev. 2008;65 (4):379-436. doi:10.1177/1077558708317802

11. Weiner BJ. A theory of organizational readiness for change. Implement Sci. 2009;4(1):67. doi:10.1186/1748-5908-4-67

12. Eby LT, Adams DM, Russell JE, Gaby SH. Perceptions of organizational readiness for change: factors related to employees' reactions to the implementation of team-based selling. Human Relations. 2000;53 (3):419-442. doi:10.1177/0018726700533006

13. Gale NK, Heath G, Cameron E, Rashid S, Redwood S. Using the framework method for the analysis of qualitative data in multi-disciplinary health research. BMC Med Res Methodol. 2013;13(1):117. doi:10.1186/1471-2288-13-117
14. Atukunda EC, Mugyenyi GR, Atuhumuza EB, et al. Factors associated with pregnancy intentions amongst postpartum women living with HIV in Rural Southwestern Uganda. AIDS Behav. 2019;23 (6):1552-1560. doi:10.1007/s10461-018-2317-9

15. Atukunda EC, Mugyenyi GR, Musiimenta A, et al. Structured and sustained family planning support facilitates effective use of postpartum contraception amongst women living with HIV in South Western Uganda: a randomized controlled trial. J Glob Health. 2021;11. doi:10.7189/jogh.11.04034

16. Atukunda EC, Musiimenta A, Musinguzi N, et al. Understanding patterns of social support and their relationship to an ART adherence intervention among adults in rural Southwestern Uganda. AIDS Behav. 2017;21(2):428-440. doi:10.1007/s10461-016-1559-7

17. Atukunda EC, Matthews LT, Musiimenta A, et al. Understanding the effect of a healthcare provider-led family planning support intervention on contraception use and pregnancy desires among postpartum women living with HIV in Southwestern Uganda. AIDS Behav. 2021;1-11. doi:10.1007/s10461-021-03380-z

18. Atukunda EC, Mugyenyi GR, Obua C, et al. Provision of family planning vouchers and early initiation of postpartum contraceptive use among women living with HIV in southwestern Uganda: a randomized controlled trial. PLoS Med. 2019;16(6):e1002832. doi:10.1371/journal.pmed.1002832

19. Beebwa E, Muzoora C, Ashaba S, Groves S, Atwine F. Knowledge, attitude, and preferred strategies towards HIV/AIDS prevention among adolescents attending secondary schools in South Western Uganda. Afr Health Sci. 2021;21(3):1067-1073. doi:10.4314/ahs. v21i3.14

20. Kemigisha E, Zanoni B, Bruce K, et al. Prevalence of depressive symptoms and associated factors among adolescents living with HIV/ AIDS in South Western Uganda. AIDS Care. 2019;31 (10):1297-1303. doi:10.1080/09540121.2019.1566511

21. Nampijja D, Kumbakumba E, Bajunirwe F, Kiwanuka J. Dyslipidemia and its Correlates among HIV infected children on HAART attending Mbarara Regional Referral hospital. Int Clin Pathol j. 2017;4:3. doi:10.15406/icpj1.2017.04.00098

22. Nabulo H, Ruzaaza G, Mugabi F, Bajunirwe F. Perceptions on preeclampsia and eclampsia among senior, older women, in rural Southwestern Uganda. J Global Health Rep. 2021;5:e2021009. doi:10.29392/001c.19464

23. Najjuma JN, Brennaman L, Nabirye RC, et al. Adherence to antihypertensive medication: an interview analysis of Southwest Ugandan patients' perspectives. Ann Global Health. 2020;86:1. doi:10.5334/aogh.2904

24. Migisha R, Agaba DC, Katamba G, et al. Prevalence and correlates of cardiovascular autonomic neuropathy among patients with diabetes in Uganda: a hospital-based cross-sectional study. Glob Heart. 2020;15:1. doi:10.5334/gh.765

25. Migisha R, Agaba DC, Katamba G, Manne-Goehler J, Muyingo A, Siedner MJ. Postural changes in blood pressure among patients with diabetes attending a referral hospital in southwestern Uganda: a cross-sectional study. BMC Cardiovasc Disord. 2021;21(1):1-9. doi:10.1186/s12872-021-02022-5

26. Migisha R, Agaba DC, Katamba G, Miranda SL, Muyingo A, Siedner MJ. High prevalence of prolonged QTc interval among individuals in ambulatory diabetic care in southwestern Uganda. Int J Diabetes Dev Ctries. 2021;15:1-7.

27. Patrick KS, Siraj S, Kakule M, David CA, Richard M. High prevalence of uncontrolled hypertension among patients with type 2 diabetes mellitus: a hospital-based cross-sectional study in southwestern Uganda. PAMJ. 2021;39:142. doi:10.11604/pamj.2021.3 9.142.28620

28. Agaba DC, Migisha R, Katamba G, Ashaba S. Cardio-metabolic abnormalities among patients with severe mental illness at a Regional Referral Hospital in southwestern Uganda. PLoS One. 2020;15(7):e0235956. doi:10.1371/journal.pone.0235956 
29. Agaba DC, Migisha R, Namayanja R, et al. Prevalence and associated factors of metabolic syndrome among patients with severe mental illness attending a tertiary Hospital in Southwest Uganda. Biomed Res Int. 2019;2019:1096201. doi:10.1155/2019/1096201

30. Agaba DC, Migisha R, Lugobe HM, Katamba G, Ashaba S. A 10 -year risk of cardiovascular disease among patients with severe mental illness at mbarara regional referral Hospital, Southwestern Uganda. Biomed Res Int. 2020;2020:1-6.

31. Abdallah A, Demaerschalk BM, Kimweri D, et al. A comparison of the Full Outline of Unresponsiveness (FOUR) and Glasgow Coma Scale (GCS) scores in predicting mortality among patients with reduced level of consciousness in Uganda. Neurocrit Care. 2020;32 (3):734-741. doi:10.1007/s12028-019-00806-4

32. Abdallah A, Chang JL, O'Carroll CB, et al. Stroke in human immunodeficiency virus-infected individuals in Sub-Saharan Africa (SSA) a systematic review. J Stroke Cerebrovasc Dis. 2018;27 (7):1828-1836. doi:10.1016/j.jstrokecerebrovasdis.2018.02.016

33. Lugobe HM, Muhindo R, Kayondo M, et al. Risks of adverse perinatal and maternal outcomes among women with hypertensive disorders of pregnancy in southwestern Uganda. PLoS One. 2020;15 (10):e0241207. doi:10.1371/journal.pone.0241207

34. Nakku D, Nyaiteera V, Llowet E, et al. HIV status and hearing loss among children between 6 and 12 years of age at a large urban health facility in south western Uganda. Int $J$ Pediatr Otorhinolaryngol. 2017;101:172-177. doi:10.1016/j.ijporl.2017.08.011

35. Orikiriza P, Rukundo GZ, Kayanja A, Bazira J. clinical conditions of hospitalized older adult patients and their outcomes in a regional referral hospital in Southwestern Uganda. J Aging Res. 2020;2020. doi:10.1155/2020/6830495

36. Namagga JK, Rukundo GZ, Voss JG. Prevalence and risk factors of $\mathrm{HIV}$-associated neurocognitive disorders in rural Southwestern Uganda. J Assoc Nurse AIDS Care. 2019;30(5):531. doi:10.1097/ JNC.0000000000000036

37. Namagga JK, Rukundo GZ, Niyonzima V, Voss J. Depression and HIV associated neurocognitive disorders among HIV infected adults in rural southwestern Uganda: a cross-sectional quantitative study. BMC Psychiatry. 2021;21(1):350. doi:10.1186/s12888-021-03316-w

38. Abdallah A, Chang JL, O'Carroll CB, et al. Validation of the Intracerebral Hemorrhage Score in Uganda. Stroke. 2018;49 (12):3063-3066. doi:10.1161/STROKEAHA.118.022057

39. Ashaba S, Cooper-Vince C, Maling S, Rukundo G, Akena D, Tsai A. Internalized HIV stigma, bullying, major depressive disorder, and high-risk suicidality among HIV-positive adolescents in rural Uganda. Global Mental Health. 2018;5:e22.

40. Ashaba S, Kaida A, Coleman JN, et al. Psychosocial challenges facing women living with HIV during the perinatal period in rural Uganda. PLoS One. 2017;12(5):e0176256. doi:10.1371/journal. pone. 0176256

41. Ashaba S, Cooper-Vince C, Vořechovská D, et al. Development and validation of a 20 -item screening scale to detect major depressive disorder among adolescents with HIV in rural Uganda: a mixed-methods study. SSM-Population Health. 2019;7:100332. doi:10.1016/j.ssmph.2018.100332

42. Ashaba S, Cooper-Vince CE, Vořechovská D, et al. Community beliefs, HIV stigma, and depression among adolescents living with HIV in rural Uganda. Afr $j$ AIDS Res. 2019;18(3):169-180. doi:10.2989/16085906.2019.1637912

43. Ashaba S, Kakuhikire B, Vořechovská D, et al. Reliability, validity, and factor structure of the Hopkins Symptom Checklist-25: population-based study of persons living with HIV in rural Uganda. AIDS Behav. 2018;22(5):1467-1474. doi:10.1007/s10461017-1843-1

44. Ashaba S, Kaida A, Burns BF, et al. Understanding coping strategies during pregnancy and the postpartum period: a qualitative study of women living with HIV in rural Uganda. BMC Pregnancy Childbirth. 2017;17(1):138. doi:10.1186/s12884-017-1321-9
45. Kirabira J, Forry BJ, Fallen R, Sserwanga B. Perceived stigma and school attendance among children and adolescents with epilepsy in South Western Uganda. Afr Health Sci. 2020;20(1):376-382. doi:10.4314/ahs.v20i1.43

46. Kirabira J, Lam A, Ssuna B, Rukundo GZ. Psychiatric disorders among children and adolescents with active epilepsy in southwestern Uganda. PAMJ-One Health. 2020;3:9. doi:10.11604/pamj-oh. 2020.3.9.25146

47. Ainamani HE, Alele PE, Rukundo GZ, et al. Caregiving burden and mental health problems among family caregivers of people with dementia in rural Uganda. Global Mental Health. 2020;7. doi:10.1017/gmh.2020.7

48. Kakongi N, Rukundo GZ, Gelaye B, Wakida EK, Obua C, Okello ES. Exploring pathways to Hospital Care for Patients with Alzheimer's disease and related dementias in rural South Western Uganda. BMC Health Serv Res. 2020;20:1-12. doi:10.1186/s12913-020-05365-5

49. Nankinga PN, Maling S, Chemali Z, Wakida EK, Obua C, Okello ES. Informal support for people with Alzheimer's disease and related dementias in rural Uganda: a qualitative study. Int $J$ Ment Health Syst. 2020;14(1):1-11. doi:10.1186/s13033-020-00364-9

50. Kamoga R, Rukundo GZ, Wakida EK, Nakidde G, Obua C, Buss SS. Dementia assessment and diagnostic practices of healthcare workers in rural southwestern Uganda: a cross-sectional qualitative study. BMC Health Serv Res. 2019;19(1):1005. doi:10.1186/s12913-0194850-2

51. Owokuhaisa J, Rukundo GZ, Wakida E, Obua C, Buss SS. Community perceptions about dementia in southwestern Uganda. BMC Geriatr. 2020;20:1-12. doi:10.1186/s12877-020-01543-6

52. Mubangizi V, Maling S, Obua C, Tsai AC. Prevalence and correlates of Alzheimer's disease and related dementias in rural Uganda: crosssectional, population-based study. BMC Geriatr. 2020;20(1):48. doi:10.1186/s12877-020-1461-z

53. Rukundo GZ, Byakwaga H, Kinengyere A, Bapolisi AM, Betancourt M, Akena D. Prevalence and factors associated with suicide among medical professionals in low/middle-income countries: a systematic review protocol. BMJ Open. 2019;9(8):e028884. doi:10.1136/bmjopen-2018-028884

54. Rukundo GZ, Kemigisha E, Ocan M, Adriko W, Akena DH. A systematic review of the risk factors for suicidal ideation, suicidal attempt and completed suicide among children and adolescents in sub-Saharan Africa between 1986 and 2018: protocol for a systematic review of observational studies. Syst Rev. 2018;7(1):230. doi:10.1186/s13643-018-0901-8

55. Wakida EK, Talib ZM, Akena D, et al. Barriers and facilitators to the integration of mental health services into primary health care: a systematic review. Syst Rev. 2018;7(1):211. doi:10.1186/s13643018-0882-7

56. Wakida EK, Akena D, Okello ES, et al. Barriers and facilitators to the integration of mental health services into primary health care: a systematic review protocol. Syst Rev. 2017;6(1):1-7. doi:10.1186/ s13643-017-0561-0

57. Wakida EK, Ocan M, Rukundo GZ, et al. Adherence to Clinical guidelines in integration of mental health services into primary health care in Mbarara, Southwestern Uganda: a medical record review. International Journal of Mental Health Systems. 2021;15(1). doi:10.1186/s13033-021-00488-6.

58. Mugabo L, Rouleau D, Odhiambo J, et al. Approaches and impact of non-academic research capacity strengthening training models in sub-Saharan Africa: a systematic review. Health Res Pol Syst BioMed Central. 2015;13:30. doi:10.1186/s12961-015-0017-8

59. Auranen O, Nieminen M. University research funding and publication performance-An international comparison. Res Policy. 2010;39 (6):822-834. doi:10.1016/j.respol.2010.03.003

60. Ramsay A, Harries A, Zachariah R, et al. The structured operational research and training initiative for public health programmes. Public Health Action. 2014;4(2):79-84. doi:10.5588/pha.14.0011 
61. Herscovitch L, Meyer JP. Commitment to organizational change: extension of a three-component model. J Appl Psychol. 2002;87 (3):474. doi:10.1037/0021-9010.87.3.474
62. Klein KJ, Sorra JS. The challenge of innovation implementation. Acad Manage Rev. 1996;21(4):1055-1080. doi:10.5465/amr.199 6.9704071863

\section{Publish your work in this journal}

Advances in Medical Education and Practice is an international, peerreviewed, open access journal that aims to present and publish research on Medical Education covering medical, dental, nursing and allied health care professional education. The journal covers undergraduate education, postgraduate training and continuing medical education including emerging trends and innovative models linking education, research, and health care services. The manuscript management system is completely online and includes a very quick and fair peer-review system. Visit http://www.dovepress.com/testimonials.php to read real quotes from published authors. 